Facts, fantasies, foundations, formations, fights, and fallouts of global consumer culture: An introduction to the special issue

\begin{tabular}{|r|l|}
\hline Journal: & International Marketing Review \\
\hline Manuscript ID & IMR-02-2019-0057 \\
\hline Manuscript Type: & Original Article \\
\hline Keywords: & $\begin{array}{l}\text { global consumer culture, globalization, global brands, local brands, } \\
\text { consumer identity }\end{array}$ \\
\hline
\end{tabular}




\title{
Facts, fantasies, foundations, formations, fights, and fallouts of global consumer culture: An introduction to the special issue
}

\author{
Purpose - The paper discusses contributions to the IMR special issue on "Global Consumer \\ Culture: The Evolving Nature of Global and Local Consumption" \\ Design/methodology/approach - The approach is conceptual with illustrative examples.
}

Findings - The reader finds a mélange of what we term the 6 Fs of global consumer culture: facts, fantasies, foundations, formations, fights, and fallouts. Offering many novel insights, the papers published in the special issue embody the burgeoning landscape of issues concerning the evolving nature of global and local consumer cultures, their effects on consumers' underlying decision-making processes, as well as on how these developments are precipitating a paradigm change in global and local branding approaches.

Originality/value - This introduction integrates the contributions made to the special issue along 6 facets by discussing future directions for research on global consumer culture.

Keywords: Global consumer culture, globalization, global brands, local brands, consumer identity

Paper type - Discussion paper 


\section{Introduction}

Globalization is undoubtedly changing the way businesses operate. As we noted in the call for papers and as clearly vindicated by the contents of this special issue, globalization is also proving to have far-reaching repercussions on the consumer landscape.

Since the 1980s, innumerable books, papers, and articles have been published debating the purported effects of globalization on society. Nevertheless, from an empirical standpoint, researchers have primarily focused on the cultural changes experienced by minority groups, and have only recently shifted their focus to examining the societal transformations being experienced by mainstream populations due to the forces of globalization. Foreign traveling, multinational marketing activities, transnational media, and other forces are the cultural intermediaries (Bourdieu, 1984) that are interlacing societies around the world. A growing proportion of consumers are relentlessly subjected to cultural forces from abroad, without needing to leave their native countries. In many respects, these consumers no longer necessarily live their lives solely in accordance with the values, norms and behavioral expectations of their local culture.

These transformations are perceptible; however, they are proceeding unevenly and intricately, within and across borders, consumer groups and consumption contexts. In order to model the vicissitudes in consumer behavior arising from globalization, the predominant approach taken by international marketing researchers has been to conceptualize consumers' positive and negative dispositions toward foreign countries and globalization (Bartsch, Riefler, \& Diamantopoulos, 2016). Among others, the literature describes consumers as ethnocentric (Shankarmahesh, 2006; Sharma, 2015; Siamagka \& Balabanis, 2015), cosmopolitan (Cleveland, Papadopoulos, \& Laroche, 2011), xenocentric (Balabanis \& Diamantopoulos, 2016), global 
citizens (Strizhakova, Coulter, \& Price, 2008), or as having a global identity (Tu, Khare, \& Zhang, 2012). These consumer groups offer theoretically well-suited segments which are distinguishable based on their consumption behavior (Riefler, 2012; Strizhakova, Coulter, \& Price, 2012), reflected in their susceptibility toward global, foreign, and local brands.

Indeed, the inherent global, foreign, and local character of brands represents distinguishing criteria that companies may leverage to attract said consumer groups (Cleveland, Laroche, \& Papadopoulos, 2015; Guo, 2013; Özsomer \& Altaras, 2008). To this end, firms manipulate signals, including associations toward or away from particular cultures, for positioning products and persuading consumers (Prince, Davies, Cleveland \& Palihawadana, 2016), recognizing that across borders, consumers use shared sets of consumption-related symbols as vehicles to express their domestic, ethnic/foreign, global and/or other social identities. They do so in part by drawing from the foreign products readily available in many domestic markets.

Contrary to the inexorable homogenization of behavior famously predicted by Levitt (1993), researchers are detecting the resilience of particularized, place-based cultures as well as the emergence of sizable consumer segments that appear to favor local brands, either generally or for specific contexts, over their foreign and global counterparts (Steenkamp \& de Jong, 2010; Zeugner-Roth, Žabkar, \& Diamantopoulos, 2015). The later trend is forcing companies to reconsider their strategies and find ways of responding to the changing nature of global and local branding. Identifying the role consumer dispositions play in this paradigm shift is a first step in accommodating the evolving nature of global and local consumption. Carving up the consumer landscape into global and local segments is further complicated by the fact that the individual consumer is increasingly fragmented: with an identity and exhibiting a consumption lifestyle that 
is thoroughly global in some situations, local in other circumstances, hybridized/creolized in certain settings, and perhaps none of the above in still other conditions

Thus, the globalization of markets provides international companies with a paradigm that promotes global brand portfolios over local ones. Consequently, companies are adapting their marketing strategies to target evolving global consumer segments that are favorably disposed to foreign and/or global market offerings (Papadopoulos \& Martín Martín, 2011), as well as disguising or otherwise downplaying the brand or parent firm's globality or foreign origin in order to attract and serve ethnic, national and parochial consumer segments.

Against this backdrop, as stated in the call for papers, the current state of the literature remains fragmented, and there are many glaring gaps in our knowledge that warrant immediate attention. In particular, there is a dearth of research that seeks to better understand the distinctions among the numerous conceptualizations of consumer dispositions relating to cultural in- and out- groups (and in turn, how these combine to differentially drive brand preferences across product categories and consumption contexts), as well as their antecedents (e.g., how do personality dimensions shape the adaptation of dispositions); how multiple, potentially conflicting social identities interact and shape consumer behavior; the interaction among and commutation of global, foreign and local consumer cultures; the appropriation of global consumer culture (GCC) elements and their indigenization by local societies; and finally, the prospective advent of multiple, regional forms of global consumer culture (for example, to what extent do Western and Eastern variants of GCC detected by researchers overlap?).

The papers comprising this special issue have realized our objective, which was to provide scholars with a platform to share important, potentially controversial intuitions, which push the boundaries of our understanding of global and local consumer cultures and their joint 
influence on many consumer behaviors. The statistics of this special issue testifies to the reality of globalization. Aggregating the original competitive submissions and revisions, invited essays, invited commentaries on these essays, and commentary response notes, there were 96 papers submitted to our special issue, each of which were appraised by the four guest editors based in France, Canada, South Korea, and the United Kingdom, as well as some 67 anonymous reviewers from universities in 16 nations.

The end product of this special issue comprises seven original articles, three invited papers, nine commentaries on the invited papers, and three reply notes, authored by 35 scholars around the world. These 22 unique works constitute a mélange of phenomenon that we have elected to label the 'six Fs' of global consumer culture: (1) facts, (2) fantasies, (3) foundations, (4) formations, (5) fights, and (6) fallouts (see Figure 1). The ensuing paragraphs briefly describe each facet, and provides a snapshot of the contributions made by each work comprising this special issue, as falling under each facet. Unless noted otherwise, authors' names pertain to publications in this issue.

[Figure 1 about here]

\section{Facts}

'Facts' encompass bits of knowledge about GCC, in a general sense that are more or less agreed upon by scholars, such as the existence of positive and negative consumer dispositions towards foreign countries, peoples, and globalization; the emergence of ethnic diasporas and other consumer segments that span national frontiers, as well as the success of global brands. In this issue Steenkamp, Belk, Samiee, Magnusson and Westjohn, Mandler, and Davvetas and Halkias recap (a) the history of global branding research, (b) our treatment of global and local brands in our research endeavors, and, building on this wisdom, (c) articulate potential directions 
for the future. Steenkamp's birds-eye view of the past and current landscapes of globalization, and the accompanying commentaries provided by Belk and Samiee, put our current understanding of globalization (and consequences for marketing practice) into proper perspective. These authors, along with Cleveland and Bartsch's piece on the epistemology and ontology of GCC, highlight critical research avenues requiring attention; for example, for insights into what appears to be a growing paradigm shift from GCC depicted as a predominantly Western phenomena, to GCC representing a mélange of influences from other regions, in particular, from those Eastern economies that are enmeshed in the global economy and thus providing many ingredients that are seasoning today's GCC (or GCCs).

The empirical papers in this special issue also provide contemporaneous insights on the intersection of globalization, branding, and culture. Davvetas and Halkias expand upon the consequences of perceived brand globalness and localness by employing a categorization theory viewpoint. Their findings suggest that these designators have a differential impact on stereotypical consumer perceptions of warmth and competence, subsequently shaping consumerbrand relationships. Samiee calls for more conceptual work on defining global brands, and he emphasizes the need for a generally accepted operational definition of the construct of globalness. In a similar vein, Magnusson and Westjohn advocate a more nuanced understanding of global branding research, by reminding us that in many cases truly global brands are often marginal when it comes to consumer preferences and market share considerations. By extending Steenkamp's and colleagues (2003) seminal work on perceived brand globalness, Mandler's work answers these calls, by distinguishing three global brand facets that drive consumer responses, namely: (a) perceived market reach, (b) perceived standardization, and (c) global consumer positioning. 


\begin{abstract}
Fantasies
'Fantasies' denote doubts about the reality of GCC; specifically, perceptions that
\end{abstract} researchers and scholars are deluded by the presumed existence of GCC, and concomitant global brands. In this issue, several conceptual pieces, commentaries, and replies address the legitimacy of GCC. In their conceptual review of GGC, Cleveland and Bartsch deliberate the literature that dismisses the notion of GCC. Their standpoints are challenged in separate commentary pieces by de Mooij, and Torelli and Stoner. The veracity of GCC is further put into perspective by Steenkamp, against the backdrop of widespread assaults being witnessed against the neoliberal order that has propelled the globalization of market economies for the past 40 years.

The marketing landscape has undoubtedly experienced momentous changes as economies and cultures have become ever more integrated. The forces driving globalization have given rise to increasing cultural diversity in many places (Torelli and Stoner); yet, in the wake of these transformations, a seemingly growing proportion of consumers are revealing disenchantment with globalization, seeking refuge in their home country cultures. Protectionist policies are on the rise (Steenkamp). Brexit, America's withdrawal from the Trans-Pacific Partnership, growing support for extremist parties in Europe, as well increasing tensions among China, Russia, and the U.S. all attest to this shift in public opinion. These developments undermine support for Levitt's (1983) contention of the worldwide convergence of consumer preferences; however, as argued by Cleveland and Bartsch in their reply commentary, increasing cultural diversity may, in fact, stimulate the proliferation of different forms of GCC as reflected by its alternation with and alteration of, national cultures. From a marketing practice standpoint, various forms of cultural mixing ensuing from the psychology of globalization (Torelli and Stoner), opens new avenues for segmenting and targeting consumers in terms of their multifarious or hybridized cultural 
identities, as opposed to merely their sense of national vs. global belongingness. People can consolidate themselves in many different ways, and, as testified by human history, it is premature to assume that countries are any more natural as the organizational unit than social bodies above (empires, supranational, global, religions) or below (tribes, cities, neighborhoods) the nation-state (Harari, 2018).

\section{Foundations \& Formations}

Whereas, 'Foundations' represent the drivers of GCC, in terms of various intertwined dimensions of global cultural flow incorporating people, media, ideas, technology, and capital (Appadurai, 1990); 'Formation' embodies the inculcation of GCC into the individual consumer's self-concept (Arnett, 2002), and accounts for how individuals acculturate to GCC (Cleveland \& Laroche, 2007). Formation also describes the manner of positioning of global, foreign, and local brands and the evolution of companies' brand portfolios. These topics are discussed at length in this special issue.

As noted, cultural diversity and cultural mixing are on the rise, promoting the dissemination of multiple GCCs, which calls for differential brand positioning strategies that appropriately target a new mixture of cultural identities in the consumption landscape. Papers by Strizhakova and Coulter, Torelli and Stoner, and Cleveland and Bartsch discuss the psychology of globalization as a mixture of cultural identities that requires a more nuanced understanding of the different combinatory elements of consumer identities and their responses to GCC. Belk raises the need to consider consumers' appropriation and adaptation of elements of GCC in the development of what Wilk (1995, p. 115) has labelled global "structures of common differences". Consumers' patterns of hybridizing, creolizing, and glocalizing aspects of consumption is demonstrated by Dey and colleagues in their study of ethnic minorities' 
acculturation in the multicultural environment of a global city, and the repercussions for food consumption patterns. From a geographic perspective, Stöttinger and Penz study the adoption of a set of territorial identities (i.e., ethnic, national, and regional identities) in daily life and consumption situations. These empirical findings, as well as the conceptual papers authored Batra and $\mathrm{Wu}$, Strizhakova and Coulter, and Westjohn and Magnusson, highlight the need for researchers to consider the complex set of different identities at play on a global, cultural, national, local, and regional level in both a humanistic and consumption context.

Globalization stemming from evolving technoscapes (Appadurai, 1990) and the nigh ubiquity of the Internet, implies researching consumers' consumption choices beyond tangible goods. Özsomer provides compelling arguments for considering networked digital technologies (DNT) as current and future key components in the formation of GCC. Digital connectivity allows consumers to participate in and share their consumption with globally spanning networks, which in turn provides input into a global exchange of culture and values. From a business standpoint, burgeoning interconnectivity stimulates competition among marketplace actors. Global market penetration, hitherto costly and therefore the preserved domain of a minority of (mostly) multi-national corporations, is now a distinct opportunity for smaller companies or niche brands readily having access to networks of like-minded consumers willing to participate in the global discourse, as detailed in commentaries by Özsomer, and Steenkamp. With their empirical paper, Makri, Papadas, and Schlegelmilch meaningfully extend the knowledge base by investigating how consumers' global and local identities impact the motivation and usage of global digital brands (i.e., the use of social networking sites) in a digitalizing society.

Another key consideration regarding the foundations and formations of GCC concerns the reference point that marketing research has been taking in the past, as noted in the 
commentaries provided by Papadopoulos, and Özsomer. Most research focuses on affluent consumers in the economically-developed and newly industrialized societies of the West and East, to the neglect of research on consumers from less affluent parts of the world that now, thanks to mobile phones, have the (digital) means to participate in the global discourse. To this end, both Papadopoulos and Özsomer stress the need to consider not only emerging market consumers' participation in GCC, but also that of consumers from so-called "bottom of the pyramid" (BOP) market segments. So far, the participation, contribution, and aspirations of BOP segments remain understudied, despite their readiness to participate in the global conversation (Prahalad, 2005).

Fights

'Fights' represent resistance to perceived globalization as well as identity and marketplace counter-reactions to GCC and global brands, respectively. As noted previously under 'Fantasies of GCC', around the world there are signs of growing concerns with globalization, including consumers' apprehensions about the perceived ascendency of global brands relative to cherished local counterparts, and more broadly, the resurgence of nationalism (Ghemawat 2017). Not only does this raise doubts about the proliferation of GCC, but also suggests that we may need to reexamine some of our assumptions about international marketing theory and from a practical standpoint, advocate that managers make radical adjustments to their brand portfolio strategies, such as by emphasizing the contribution made by a given (global) brand to the (local) economy, as described in papers by Steenkamp, as well as by Magnusson and Westjohn.

As described by Steenkamp, the efforts of global brands to localize elements of the brand positioning strategies is but one direct consequence of the retrenchment of local consumption 
preferences, practiced by some consumers as ways of protecting their national interests. Bizumic investigates the relationship between the general conceptualization of ethnocentrism, as a broad social-psychological concept concerning ethnicity, and consumer ethnocentrism, the well-studied notion of consumer rejection of foreign products in favor of domestic products. The study demonstrates that ethnocentrism's multiple facets may be important drivers of 'consumer product nationalism' - Bizumic shows that 'consumer ethnocentrism' is just 'product nationalism', since consumer ethnocentrism has no explicit ethnic component, and is singularly focused on product choices and ignores other consumer actions. Bizumic also argues that ethnocentrism's dimensions may shape numerous other consumer-oriented outcomes, in which case, there is a need to investigate in more depth whether and how ethnocentrism shapes multiple reactions to GCC. Westjohn and Magnusson expand on these concerns by advocating for an expanded conceptualization of consumer identities - that is, beyond simplistic and possibly outmoded global-local, and foreign-domestic dichotomies - in favor of more nuanced designators resulting from pan-national, state, or even regional identities. Stöttinger and Penz (this issue) provide a first empirical impetus to move the field towards this direction.

\section{Fallouts}

Finally, 'Fallouts' symbolizes other long-term outcomes of GCC — as well as resistance thereto described above - for individual consumers, society, and commerce. This special issue includes two empirical investigations of consumer acculturation, each under the premise of different contextual factors. Dey and colleagues' study of immigrants' food consumption patterns within a culturally diverse landscape show that these consumers employ sundry strategies to safeguard and embrace ethnic, host, and foreign culture identities in their daily life. Okazaki and colleagues offer a unique take on consumers' embrace of GCC. By invoking terror 
management theory, they investigate Japanese consumers' reactions to potentially lifethreatening events; specifically, in terms of knockdown effects on consumption choices. Their findings indicate that consumers' outward-orientation towards GCC are strengthened under conditions of mortality salience; that is, when they are faced with potentially life-threatening events, and that the consumption of global brands is positively connected to consumer hope.

The conceptual papers contained in this special issue conjecture several long-term outcomes of GCC. In light of the current turmoil facing globalization, marketing research and practices are calling for a renewed contemplation of localization efforts, in addition to engaging probing how consumers combine global, foreign, ethnic, and local elements for constructing social identity and for making consumption decisions (see papers in this issue by Belk, Cleveland and Bartsch, Dey et al., and Steenkamp). Creolization, which entails the appropriation of global and local elements which over time are transmuted into novel products, is advanced as a probable long-term outcome of GCC. As they navigate an increasingly complex and culturally diverse world, consumers will appropriate elements of GCC into their daily life, by associating their own meaning to them (as noted by de Mooij). Two other likely consumer responses to GGC are consumer separation and marginalization, which respectively signify consumers' outright rejection of GCC and their withdrawal from culturally induced consumption. Research on these consumer segments remains scarce, despite signs of their progression in markets around the globe. Consumers' reactions and coping mechanisms in response to the 'hyper globalization' of markets (Subramanian and Kessler, 2013) threaten international marketing practices that favor centrally coordinated marketing strategies paired with necessary local adaptions. Considerations of neo-ethnicism (Miyoshi, 1993) and anti-materialism (Holt, 1998) are challenging yet vital themes that need tackling in order to substantially advance international marketing theory. 


\section{Concluding Remarks and Word of Thanks}

The core objective of this special issue to provide scholars with a platform to share important, potentially controversial, intuitions which push the boundaries of our understanding of global and local consumer culture and their joint influences on many consumer behaviors. We, the guest editors, believe that the 22 unique contributions from 35 authors have accomplished our set goals. In the following special issue, the reader finds a mélange of what we term the 6 Fs of global consumer culture: facts, fantasies, foundations, formations, fights, and fallouts. Offering many novel insights, the papers embody the burgeoning landscape of issues concerning the evolving nature of global and local consumer cultures, their effects on consumers' underlying decision-making processes, as well as on how these developments are precipitating a paradigm change in global and local branding approaches.

Realization of this goal would not have been possible without the dedicated involvement of a global community of scholars. We are most grateful to all contributing authors and reviewers. Their expertise and time commitment to the special issue of the International Marketing Review was crucial for generating this compendium of knowledge about GCC, and for articulating many fruitful directions to further push the boundaries of the field. We offer our profound thanks to the de-anonymized reviewing team:

$\begin{array}{ll}\text { Agarwal, James } & \text { Canada } \\ \text { Alexander, Nicholas } & \text { United Kingdom } \\ \text { Arslanagic-Kalajdzic, Maja } & \text { Bosnia and Herzegovina } \\ \text { Balabanis, George } & \text { United Kingdom } \\ \text { Bartikowski, Boris } & \text { France } \\ \text { Bizumic, Boris } & \text { Australia } \\ \text { Carvalho, Sergio } & \text { Canada } \\ \text { Chao, Paul } & \text { United States } \\ \text { Chattalas, Michael } & \text { United States } \\ \text { Claus, Bart } & \text { France } \\ \text { Cruz, Angela } & \text { Australia } \\ \text { Dalgic, Tevfik } & \text { United States }\end{array}$


d'Astous, Alain

Davvetas, Vasileios

Demangeot, Catherine

Dey, Bidit

Diamantopoulos, Adamantios

Dianoux, Christian

Dimofte, Claudiu

Ding, Qing Shan

Doherty, Anne Marie

Ford, John

González, Héctor

Grunert, Klaus

Guelmami, Ziyed

Guzman, Francisco

Halkias, Georgios

Harush, Raveh

Heinberg, Martin

Hildebrand, Christian

Kipnis, Eva

Kizgin, Hatice

Kobl, Živa

Koksal, Ahmet

Li, Eric

Li, Lydia

Lisak, Alon

Magnusson, Peter

Makri, Katerina

Mandler, Timo

Micevski, Milena

Miller, Chip

Nakata, Cheryl

Özsomer, Ayşegül

Papadas, Karolos-Konstantinos

Penz, Elfriede

Poon, Patrick

Pratono, Aluisius

Riefler, Petra

Rohani, Laila

Salnikova, Ekaterina

Schlegelmilch, Bodo

Shukla, Paurav

Sitz, Lionel

Slater, Stephanie

Soutar, Geoffrey

Strizhakova, Yuliya

Szmigin, Isabelle
Canada

United Kingdom

France

United Kingdom

Austria

France

United States

United Kingdom

United Kingdom

United States

United Kingdom

Denmark

France

United States

Austria

Israel

Germany

Switzerland

United Kingdom

Netherlands

Austria

United States

Canada

China

Israel

United States

Austria

France

Austria

United States

United States

Turkey

United Kingdom

Austria

Hong Kong

Indonesia

Austria

Canada

Denmark

Austria

United Kingdom

France

United Kingdom

Australia

United States

United Kingdom 
Taylor, Charles

Veloutsou, Cleopatra

Waehning, Nadine

Wang, Weisha

Westjohn, Stanford

Yamoah, Fred

Yaprak, Attila

Zeugner-Roth, Katharina

Zolfagharian, Mohammadali
United States

United Kingdom

United Kingdom

United Kingdom

United States

United Kingdom

United States

France

United States

Fabian Bartsch (IÉSEG School of Management, Paris, France),

Mark Cleveland (University of Western Ontario, London, Canada),

Eunju Ko (Yonsei University, Seoul, South Korea),

John W. Cadogan (Loughborough University, Leicestershire, United Kingdom),

Guest Co-Editors 


\section{References}

Appadurai, A. (1990), "Disjuncture and difference in the global cultural economy”, Theory, Culture \& Society, Vol. 7 No. 2-3, pp. 295-310.

Arnett, J.J. (2002), “The psychology of globalization”, American Psychologist, Vol. 57 No. 10, pp. $774-783$

Balabanis, G., \& Diamantopoulos, A. (2016). Consumer xenocentrism as determinant of foreign product preference: A system justification Perspective. Journal of International Marketing, Vol. 24 No. 3, pp. 58-77.

Bartsch, F., Diamantopoulos, A., Paparoidamis, N. G., \& Chumpitaz, R. (2016). Global brand ownership: the mediating roles of consumer attitudes and brand identification. Journal of Business Research, Vol. 69 No. 9, pp. 3629-3635.

Bourdieu, P. (1984). Distinction: A social critique of the judgment of taste. Cambridge, MA: Harvard University Press.

Cleveland, M. and Laroche, M. (2007), “Acculturation to the global consumer culture: scale development and research paradigm", Journal of Business Research, Vol. 60 No. 3, pp. 249-259.

Cleveland, M., Papadopoulos, N., \& Laroche, M. (2011). Identity, demographics, and consumer behaviors: International market segmentation across product categories. International Marketing Review, Vol.28 No. 3, pp. 244-266.

Cleveland, M., Laroche, M., \& Papadopoulos, N. (2015). You are what you speak? globalization, multilingualism, consumer dispositions and consumption. Journal of Business Research, Vol. 68 No. 3, pp. 542-552. 
Ghemawat, P. (2017), “Globalization in the age of trump”, Harvard Business Review, August, p. 112.

Guo, X. (2013). Living in a global world: Influence of consumer global orientation on attitudes toward global brands from developed versus emerging countries. Journal of International Marketing, Vol. 21 No. 1, pp. 1-22.

Harari, Y.N. (2018). Moving beyond nationalism. In D. Franklin (Ed.), The Economist: The World in 2019. Vol. 99 91-92.

Levitt, T. (1983). The globalization of markets. Harvard Business Review, Vol. 61 No. 3, pp. 92102.

Miyoshi, M. (1993), “A borderless world? From colonialism to transnationalism and the decline of the nation-state", Critical Inquiry, Vol. 19 No. 4, pp. 726-751.

Özsomer, A., \& Altaras, S. (2008). Global brand purchase likelihood: A critical synthesis and an integrated conceptual framework. Journal of International Marketing, Vol. 16 No. 4, pp. $1-28$.

Papadopoulos, N., \& Martín Martín, O. (2011). International market selection and segmentation: perspectives and challenges. International Marketing Review, Vol. 28 No. 3, pp. 132149.

Prahalad, C.K. (2005). The fortune at the bottom of the pyramid. Pearson Education, Inc.

Prince, Melvin; Davies, Mark; Cleveland, Mark; \& Palihawadana, Dayananda (2016), Here, there, and everywhere: A study of consumer centrism. International Marketing Review, Vol. 33 No. 5, pp. 715-754. 
Riefler, P. (2012). Why consumers do (not) like global brands: The role of globalization attitude, GCO and global brand origin. International Journal of Research in Marketing, Vol. 29 No. 1, pp. 25-34.

Shankarmahesh, M. N. (2006). Consumer ethnocentrism: An integrative review of its antecedents and consequences. International Marketing Review, Vol. 23 No. 2, pp. 146172.

Steenkamp, J.-B. E. M., \& de Jong, M. G. (2010). A global investigation into the constellation of consumer attitudes toward global and local products. Journal of Marketing, Vo. 74 No. 6, pp. $18-40$.

Sharma, P. (2015). Consumer ethnocentrism: Reconceptualization and cross-cultural validation. Journal of International Business Studies, Vol. 46 No. 3, pp. 381-389.

Siamagka, N.-T., \& Balabanis, G. (2015). Revisiting consumer ethnocentrism: Review, reconceptualization, and empirical testing. Journal of International Marketing, Vol. 23 No. 3, pp. 66-86.

Strizhakova, Y., Coulter, R. A., \& Price, L. L. (2008). Branded products as a passport to global citizenship: Perspectives from developed and developing countries. Journal of International Marketing, Vol. 16 No. 4, pp. 57-85.

Strizhakova, Y., Coulter, R. A., \& Price, L. L. (2012). The young adult cohort in emerging markets: assessing their glocal cultural identity in a global marketplace. International Journal of Research in Marketing, Vol. 29 No. 1, pp. 43-54.

Subramanian, A. and Kessler, M. (2013), "The hyperglobalization of trade and its future”, SSRN Electronic Journal, Vol. 13 No. 6, pp. 1-66. 
Tu, L., Khare, A., \& Zhang, Y. (2012). A short 8-item scale for measuring consumers' localglobal identity. International Journal of Research in Marketing, Vol. 29 No. 1, pp. 3542.

Wilk, Richard (1995), "Learning to be local in Belize: Local structures of common difference," in Daniel Miller, ed., Worlds Apart: Modernity Through the Prism of the Local, London: Routledge, 110-133.

Zeugner-Roth, K. P., Žabkar, V., \& Diamantopoulos, A. (2015). Consumer ethnocentrism, national identity, and consumer cosmopolitanism as drivers of consumer behavior: A social identity theory perspective. Journal of International Marketing, Vol. 23 No. 2, pp. $25-54$. 
Figure 1. The 6 Fs of Global Consumer Culture: An Overview of the Special Issue

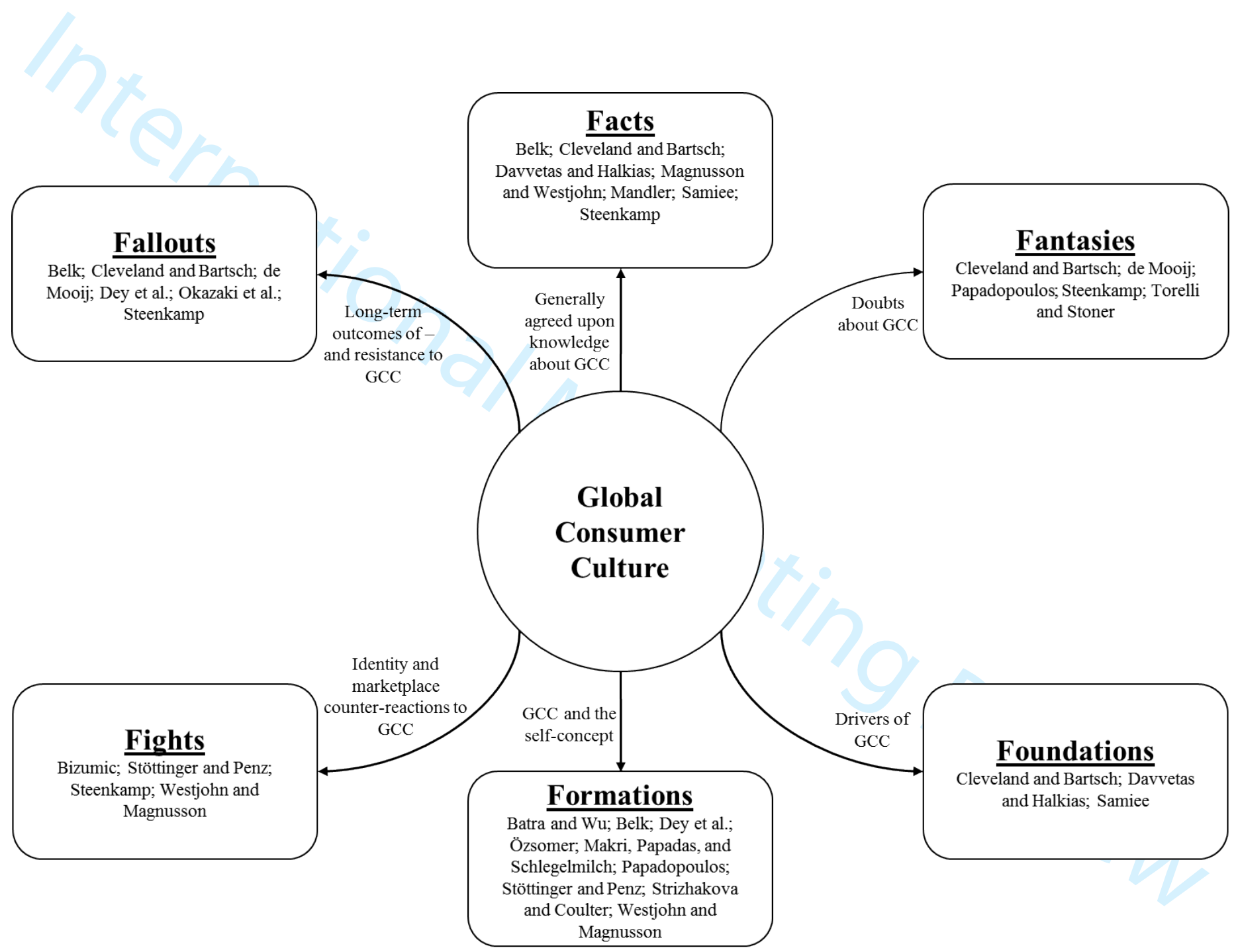

